Article

\title{
Feasibility Investigation of SIW Cavity-Backed Patch Antenna Array for Ku Band Applications
}

\author{
Onofrio Losito ${ }^{1}$, Vincenza Portosi ${ }^{1}$, Giuseppe Venanzoni ${ }^{2}$, Francesco Bigelli $^{3}$, \\ Davide Mencarelli ${ }^{4}$, Paolo Scalmati ${ }^{3}$, Chiara Renghini ${ }^{3}$, Pasquale Carta ${ }^{3}$ and \\ Francesco Prudenzano ${ }^{1, *(1)}$
}

1 Dipartimento di Ingegneria Elettrica e dell'Informazione, Politecnico di Bari Via Orabona 4, 70125 Bari, Italy; onofrio.losito@poliba.it (O.L.); vincenza.portosi@poliba.it (V.P.)

2 Dipartimento di Ingegneria, Università di Perugia, Via G. Duranti 93, 06123 Perugia, Italy; giuseppe.venanzoni@unipg.it

3 R\&D Department, Somacis Spa, Via Jesina 17, 60022 Castelfidardo, Italy; f.bigelli@somacis.com (F.B.); p.scalmati@somacis.com (P.S.); c.renghini@somacis.com (C.R.); p.carta@somacis.com (P.C.)

4 Dipartimento di Ingegneria dell'Informazione, Università Politecnica delle Marche Via Brecce Bianche, 60131 Ancona, Italy; d.mencarelli@univpm.it

* Correspondence: francesco.prudenzano@poliba.it; Tel.: +39-080-5963781

Received: 1 March 2019; Accepted: 25 March 2019; Published: 27 March 2019

\begin{abstract}
A cavity-backed microstrip patch antenna array was optimized in the Ku band. The backing cavity was designed under each patch antenna of the array in order to increase the bandwidth and minimize the intercoupling among the radiating elements. Substrate integrated waveguide (SIW) technology was employed to fabricate the above-mentioned cavity below the radiating patch. More precisely, four microstrip array antennas, made by $2 \times 2,4 \times 4,8 \times 8$, and $16 \times 16$ elements were designed, fabricated, and characterized. The measured maximum gain was $G=13 \mathrm{dBi}$, $\mathrm{G}=18.7 \mathrm{dBi}, \mathrm{G}=23.8 \mathrm{dBi}$, and $\mathrm{G}=29.2 \mathrm{dBi}$, respectively. The performance of the proposed antenna arrays was evaluated in terms of radiation pattern and bandwidth. An extensive feasibility investigation was performed even from the point of different materials/costs in order to state the potential of the engineered antennas in actual applications. The obtained results indicate that a cavity-backed microstrip patch antenna is a feasible solution for broadband digital radio and other satellite communication overall for niche applications.
\end{abstract}

Keywords: substrate integrated waveguide SIW; antenna array; cavity backed antenna; Ku band antenna

\section{Introduction}

During the last decades, an increasing research interest has been directed toward a variety of satellite services provided in the Ku-band frequency range, e.g., digital radio, TeleVision (TV) broadcasting, and broadband Internet. Moreover, new microwave communication systems designed for automotive, high velocity trains, boats, airplane radio navigation, 5G wireless, smart city, and industry 4.0 applications constitute a current research hot topic. In all of the aforesaid cases, the development of high-performance antennas can significantly contribute to increase the overall information capacity of an innovative communication system. Efficient satellite communication in the $\mathrm{Ku}$-band requires antennas with high gains and a broadband of at least $2 \mathrm{GHz}$, from 10.5 to $12.5 \mathrm{GHz}$. High performance, flat-shaped, and wall-mounted antennas that have been optimized with the aim of reducing the environmental and/or visual impact, are promising devices. Patch antenna elements are largely utilized in the fabrication of high-performance arrays. Unfortunately, as patches resonate 
at a single frequency, they typically exhibit a narrow relative bandwidth of about $2 \%$; this is a strong drawback that prevents their usage in wide-band applications.

There are various approaches to enhance the bandwidth including the employment of suspended substrates, multi-stack [1-3], and metalized baking cavities [4-7].

Substrate integrated waveguide (SIW) technology has been largely employed for the construction of couplers, filters, oscillators, amplifiers, mixers, in addition to antennas since it allows for low-cost implementation, fast prototyping, and precise manufacturing [8-19]. It can be used to improve the antenna radiation characteristics, thus obtaining better performances than those of the conventional microstrip/printed board circuits (PCB) while maintaining the typical advantages of planar technologies. In fact, SIW technology allows for low cost, lightness, easy integration with both passive and active devices, high power levels, feasible mass production, and manufacturing repeatability. Several SIW cavity-backed antennas and feeding geometries have been reported in the literature [16-25]. For example, a reconfigurable SIW Cavity-Backed Slot (SIW-CBS) antenna with a one octave tuning range and six different tuning states was presented in [16]. A new tuning method based on loading the SIW cavity with shortening posts and manipulating the field distribution within the cavity was proposed. In [17], a SIW-slot feeding structure was introduced in a fully substrate-integrated thin Fabry-Pérot cavity (FPC) antenna in order to achieve boresight radiation free of beam squint and low backward radiation levels. Moreover, a single patch with truncated corners has been developed to provide a linear polarized antenna in SIW technology for the Ku-band range of frequency [18]. This technology has been recently proposed as an example in the $57-71 \mathrm{GHz}$ band for 5G [23], X-band [24], and dual-band in K-band [25] applications.

In this paper, a broadband SIW cavity-backed microstrip patch antenna was designed and optimized for radiation in the Ku band. Starting from the antennas reported in [18,26,27], the patch geometry has been enhanced by introducing lateral cuts and asymmetric feeding of each single radiating element to obtain a wider operation band and frequency downshift. This means that the radiating elements are smaller, allowing more space for the feeding network and improving the isolation among transmission lines. In addition, the particular shape of the radiating element allows for the use of a simpler matching network to the feeding line. A $16 \times 16$ element array was designed and fabricated to obtain a pre-prototype antenna. In particular, the radiating element spacing was optimized to minimize the secondary grating lobes while using the maximum allowable space in the substrate backplane. The single element antenna as well as the antenna arrays were fabricated by using two substrates (top and bottom ones) of the same material and different thicknesses. The top substrate contained the feeding network and patches. Each patch element of the array was coupled with an optimized SIW cavity (backed) lying in the bottom substrate. At first, simple screws were employed to connect the two substrates. In the final prototypes, a prepreg press compression molding process was employed to stack the multi-layer PCB. The design was performed by employing the CST Microwave Studio $\odot$ software, and the SIW antenna prototypes were fabricated with the PCB process in the SOMACIS plant. A complete feasibility investigation is illustrated by reporting all of the steps toward the $16 \times 16$ antenna array optimization. Excellent characteristics, comparable or slightly better than those reported in $[18,26]$, were obtained. In particular, the same gain but with a wider band compared with [26], was obtained when the same number of array elements was considered. The $16 \times 16$ antenna array exhibited high gain, close to $G=29.2 \mathrm{dBi}$, and good return losses in a wide frequency region including the whole Direct Broadcast Satellite (DBS) band (i.e., in the range 10.7-12.7 GHz) and over. A practically squint-less main lobe was measured. Therefore, a $16 \times 16$ antenna array could be of practical interest in actual communication systems. Different materials have been considered in order to choose the best trade-off between the engineered prototypes.

The paper is organized as follows. Section 2 presents the design of the single cavity backed antenna; Section 3 shows the design of the antenna arrays; Section 4 describes the fabrication and the characterization of the prototypes; Section 5 details the feasibility and discussion on the material choice; and Section 6 presents our conclusions. 


\section{Single Antenna Design}

The design of high-performance antennas requires several trade-offs. High permittivity substrates can allow the construction of very compact microstrip antennas. Thick substrates with lower dielectric constants offer a better radiation efficiency and wide bandwidth, but larger sizes are needed. Further performance improvements can be obtained by employing SIW circular cavities backing the microstrip patch antennas. They also allow the suppression of surface waves, thus obtaining very high isolation from the surrounding elements of antenna arrays.

In this paper, a low-loss and low dielectric constant substrate was used. In particular, the Rogers Duroid 5880 with a dielectric constant of $\varepsilon_{\mathrm{rs}}=2.2$ and loss tangent of $\delta=0.0009$ was chosen for both (top and bottom) substrates. Among the Rogers Duroid 5880 commercially available substrates, the top substrate (on which the patch antennas were obtained via etching) had a thickness of $h_{s}=0.381 \mathrm{~mm}$ and the bottom one (including the cavity walls) had a thickness of $h_{c}=1.575 \mathrm{~mm}$; the metal layers of both substrates were $h_{m}=0.035 \mathrm{~mm}$ thick. Metalized via holes circularly spaced constitute the SIW cavity side walls, as shown in Figure 1a, which illustrates a global view, and Figure $1 \mathrm{~b}$ shows a section view of the single antenna.

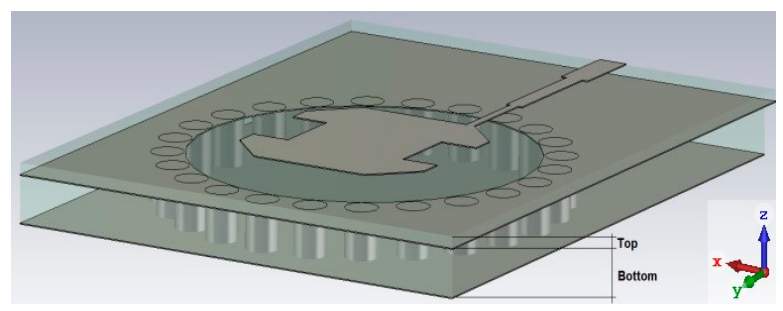

(a)

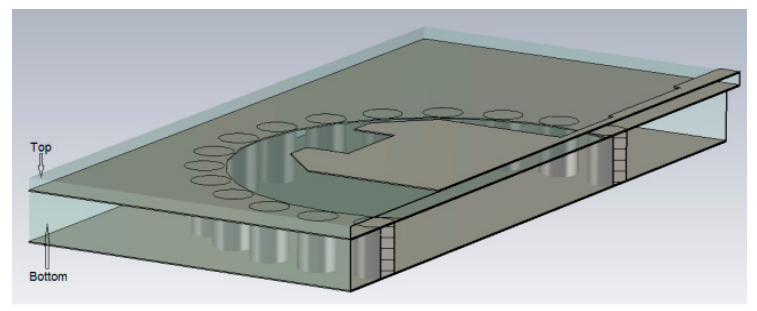

(b)

Figure 1. 3D Layout of the SIW cavity backed patch antenna: (a) global view and (b) section view.

The design was performed by using the 3D commercial software tool CST Microwave Studio@. Several simulations were performed to reach the best trade-off in terms of insertion loss reduction, bandwidth broadening, and radiation pattern characteristics.

The proposed antenna combined the attractive features of both cavity-backed patch antennas and patch antennas with truncated corners. Moreover, as a further improvement with respect to [18,26,27], two suitable cuts on the sides of the rectangular patch were designed to provide a wider frequency band and a frequency downshift. The radiating element is then smaller, allowing a more compact size of the whole array.

In order to identify the different contributions, a patch antenna without a backing cavity and with the feed located in the center is shown in Figure $2 a$. Figure $2 b$ shows the modified patch obtained by performing suitable lateral cuts and by moving the feeding microstrip in the corner of the patch. Both patches had a side $b=7.7 \mathrm{~mm}$, and a substrate thickness $h_{s}=0.381 \mathrm{~mm}$ with a metal thickness of $\mathrm{h}_{\mathrm{m}}=0.035 \mathrm{~mm}$.

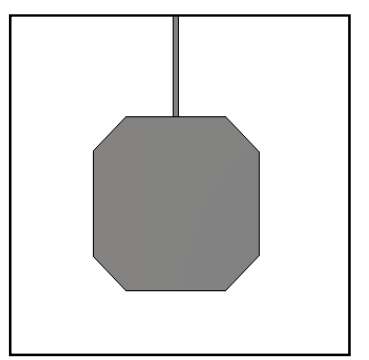

(a)

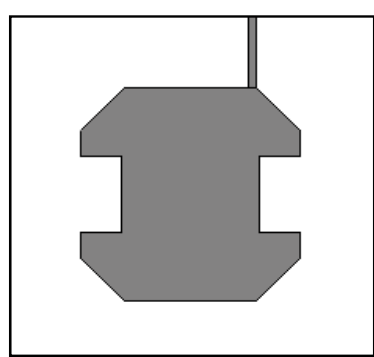

(b)

Figure 2. Layout of the linear patch antenna: (a) without lateral cuts, and (b) with lateral cuts and feeding stripline in the corner. The impedance matching network is not reported. 
The comparison between the modulus of the scattering parameter $S_{11}$ of the antenna illustrated in Figure 2a (solid curve) and the modulus of the scattering parameter $S_{11}$ of the antenna illustrated in Figure $2 b$ (dashed curve) is reported in Figure 3. For the antenna with a lateral cut and feeding strip line in the corner, the minimum of the modulus of the scattering parameter $S_{11}$ shifted toward the lower frequency of about $1 \mathrm{GHz}$ with respect to that of the antenna without a lateral cut and central feeding. The $-10 \mathrm{~dB}$ bandwidth slightly increased (about $0.1 \mathrm{GHz}$ ), changing from 11.6-12.6 GHz to 10.7-11.8 GHz.

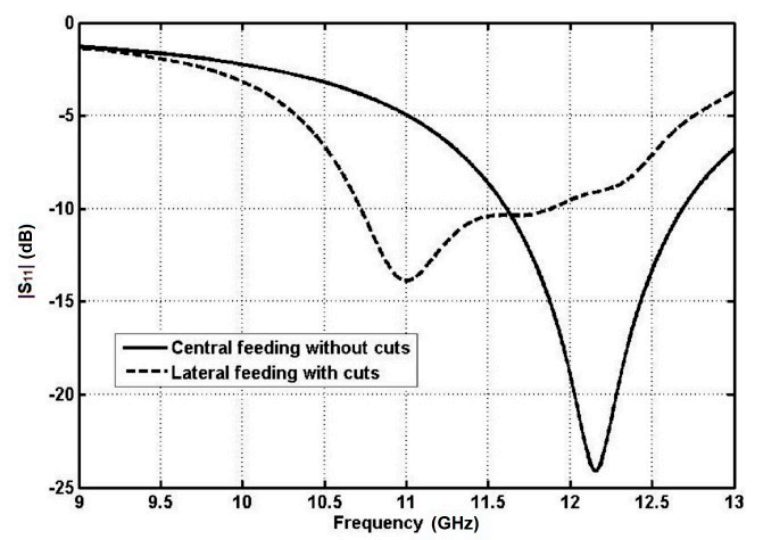

Figure 3. Simulated $\left|S_{11}\right|$ parameter versus the frequency of the patch antenna with central feeding without cuts compared with lateral feeding with lateral cuts, both without SIW backing cavity.

A suitable SIW cavity backing the patch antenna was designed. The optimized antenna patch parameters are shown in Figure 4, illustrating the top view of (a) the top layer and (b) the bottom layer, and are listed in Table 1.

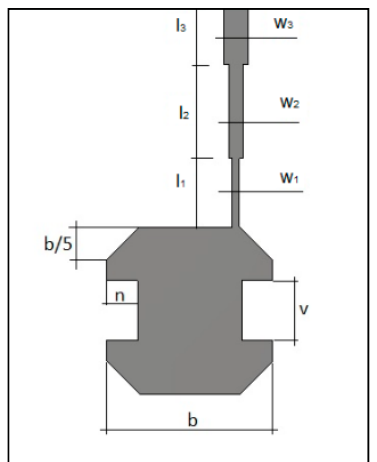

(a)

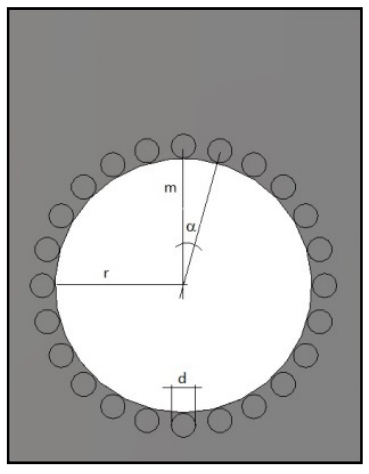

(b)

Figure 4. Layout of the SIW cavity backed antenna. (a) Top view of the first layer and (b) top view of the second layer.

Table 1. Parameters of the optimized antenna.

\begin{tabular}{cc}
\hline Parameter & Size \\
\hline $\mathrm{b}$ & $7.700 \mathrm{~mm}$ \\
$\mathrm{w} 1$ & $0.245 \mathrm{~mm}$ \\
$\mathrm{w} 2$ & $0.658 \mathrm{~mm}$ \\
$\mathrm{w} 3$ & $1.12 \mathrm{~mm}$ \\
$\mathrm{l} 1$ & $3.15 \mathrm{~mm}$ \\
$\mathrm{l} 2$ & $4.32 \mathrm{~mm}$ \\
$\mathrm{l} 3$ & $2.80 \mathrm{~mm}$ \\
$\mathrm{n}$ & $1.443 \mathrm{~mm}$ \\
\hline
\end{tabular}


Table 1. Cont.

\begin{tabular}{cc}
\hline Parameter & Size \\
\hline $\mathrm{v}$ & $2.750 \mathrm{~mm}$ \\
$\mathrm{~m}$ & $7.523 \mathrm{~mm}$ \\
$\mathrm{r}$ & $6.888 \mathrm{~mm}$ \\
$\alpha$ & $15^{\circ}$ \\
$\mathrm{d}$ & $0.620 \mathrm{~mm}$ \\
\hline
\end{tabular}

The effect of the SIW cavity backing on the antenna performance is illustrated in Figure 5. The modulus of the $S_{11}$ parameter for the patch antenna with lateral cut and feeding in the corner was reported for both cases: without (dashed curve) and with (solid curve) SIW cavity. The bandwidth for the antenna with SIW cavity was about $2 \mathrm{GHz}$ and covered the whole satellite communication $\mathrm{Ku}$ band. It is worthwhile noting (see Figures 3 and 5) that the broadband operation was obtained by a proper design of both the patch antenna with lateral cut and feeding line in the corner and SIW cavity.

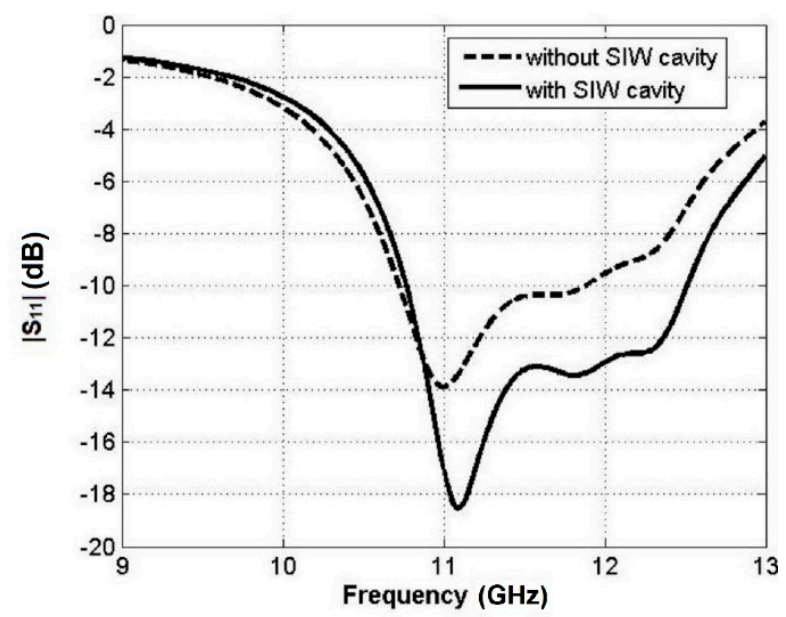

Figure 5. Simulated $\left|S_{11}\right|$ parameter versus the frequency of the patch antenna with lateral feeding and cuts, and with and without the SIW backing cavity.

The designed single element geometry is simpler with respect to other interesting cavity backed antennas reported in the literature, requiring sophisticated matching sections [19]. Moreover, a circular polarization could be obtained with slight patch shape changes.

\section{Antenna Array Design}

The most widely-used techniques for feeding microstrip patch arrays can be categorized into two main kinds: the series and the corporate (parallel) ones. Corporate feeding has a single input port and multiple feed lines arranged in parallel. Each line is terminated with an individual radiating element, e.g., a patch antenna. The basic corporate feed is composed of two-way power dividers, which can be either $3 \mathrm{~dB}$ splitters or dividers with different power at the output ports.

In this paper, the corporate feeding with $3 \mathrm{~dB}$ splitters was used, since it allows a feed with the same amplitude and phase of each radiating element. One drawback is that for long feeding lines, insertion losses cannot be negligible, this reducing the array efficiency. Arrays of uniform antennas consist of a repetition of radiating elements in a regular fashion. Each element is also located at a specific distance from the other. Figure 6 shows the base cell antenna employed in this paper to obtain the array and made by $2 \times 2$ patch antennas (four elements) spaced next to each other at $0.66 \times \lambda_{0}$ in both directions of the array plane, where $\lambda_{0}$ is the wavelength in vacuum at the central frequency of the $\mathrm{Ku}$ band $\mathrm{f}=11.7 \mathrm{GHz}$, so that $\mathrm{D}_{1}=\mathrm{D}_{2}=25.2 \mathrm{~mm}$. The input impedance of the antenna $Z_{a}=94.90 \Omega$ was matched to the line of the first two-way power divider. A quarter-wave transformer 
with $Z_{\lambda 1}=67.10 \Omega$ was used to match the lines with characteristic impedance $Z_{a}$ (matched to the single radiating element) with the line of characteristic impedance $Z_{d}=47.45 \Omega$. The quarter-wave transformers with $Z_{\lambda 2}=48.70 \Omega$ were designed to match the line with characteristic impedance $Z_{d}$ with the input line with $Z_{i}=50 \Omega$.

A larger planar array can be obtained as a regular repetition in the horizontal and vertical directions of the base cell layout of Figure 6. Following this approach, we designed the $4 \times 4,8 \times 8$, and $16 \times 16$ antenna arrays.

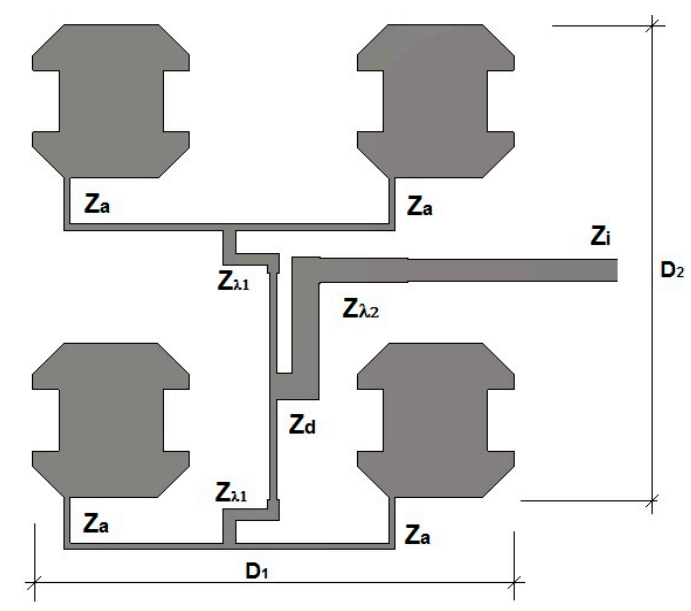

Figure 6. Layout of the base cell: patch antenna array of $2 \times 2$ elements.

\section{Antenna Fabrication and Characterization}

The single antenna prototype, manufactured by SOMACIS Spa, using a Rogers Duroid 5880 substrate with a dielectric constant $\varepsilon_{\mathrm{rs}}=2.2$ and loss tangent $\delta=0.0009$, is shown in Figure 7 . The top view (Figure $7 \mathrm{a}$ ) and the bottom view (Figure $7 \mathrm{~b}$ ) are depicted. To keep the electrical continuity between the top layer and the bottom layer, four external screws were used.

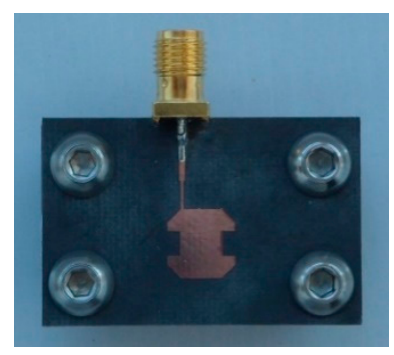

(a)

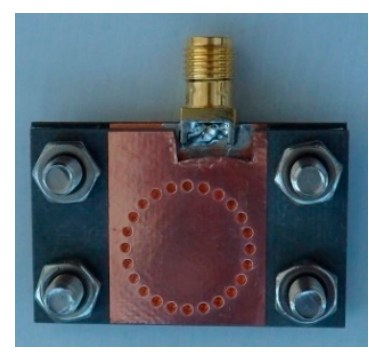

(b)

Figure 7. Prototype of the dual layer, SIW cavity backed antenna: (a) top view; (b) bottom view.

Figure 8a illustrates the simulated (solid curve) and measured (dashed curve) modulus of the $\mathrm{S}_{11}$ scattering parameter of the single SIW cavity backed antenna. The measured and simulated curves were in good agreement in the overall Ku bandwidth $(10.7-12.7 \mathrm{GHz})$. The measured $-10 \mathrm{~dB}$ bandwidth was about $2 \mathrm{GHz}$, as expected.

Figure $8 \mathrm{~b}$ illustrates the simulated (solid curve) and measured (dashed curve) gain $\mathrm{G}$ of the SIW cavity backed antenna versus the frequency. The gain of the antenna was higher than $6.8 \mathrm{~dB}$ in the frequency band 10.7-12.7 GHz. The maximum gain $\mathrm{G}=8.6 \mathrm{~dB}$ occurred at the frequency $\mathrm{f}=11.7 \mathrm{GHz}$. 


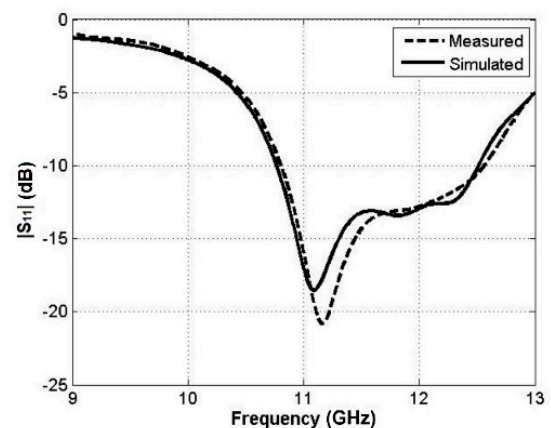

(a)

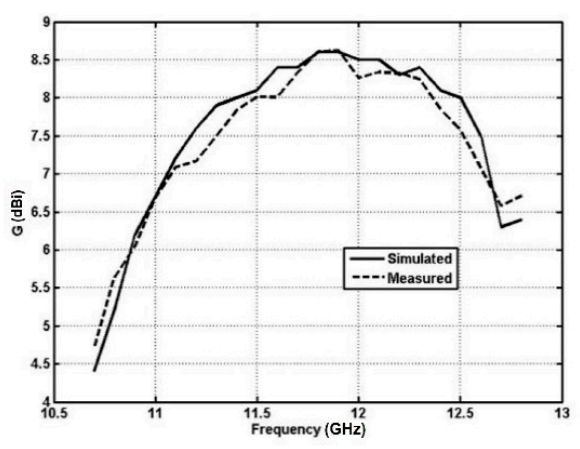

(b)

Figure 8. Measured (dashed curve) and simulated (solid curve) $\left|S_{11}\right|$ scattering parameter (a) and gain $\mathrm{G}(\mathbf{b})$ for the SIW cavity backed antenna.

Figure 9 shows the prototype of the $2 \times 2$ antenna array (base cell). Figure 10a illustrates the simulated (solid curve) and measured (dashed curve) modulus of the $S_{11}$ scattering parameter. Figure $10 \mathrm{~b}$ shows the gain versus the frequency. The measured maximum gain is $\mathrm{G}=13 \mathrm{dBi}$ close to the frequency $\mathrm{f}=12 \mathrm{GHz}$. The slight difference, less than $1.2 \mathrm{dBi}$, between the simulated and measured gain curves in the Ku band was due to both the power leakage of the feeding network and the substrate losses, which could be slightly different with respect to the values used in the simulation. As for the previous case, the good agreement between the simulated and the measured curve was apparent overall in the Ku bandwidth. The $-10 \mathrm{~dB}$ bandwidth was about $2.5 \mathrm{GHz}$.

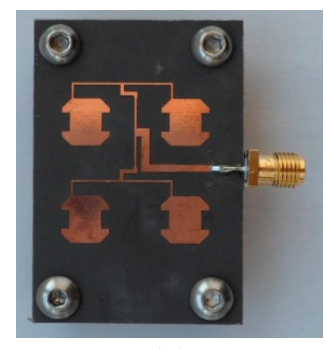

(a)

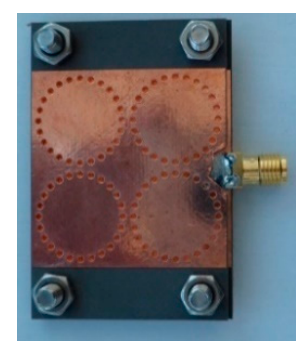

(b)

Figure 9. Prototype of the $2 \times 2$ antenna array, dual layer SIW cavity backed, antenna: (a) top view; (b) bottom view.

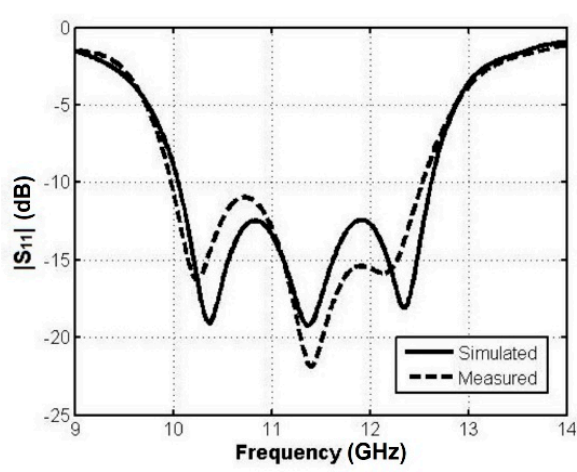

(a)

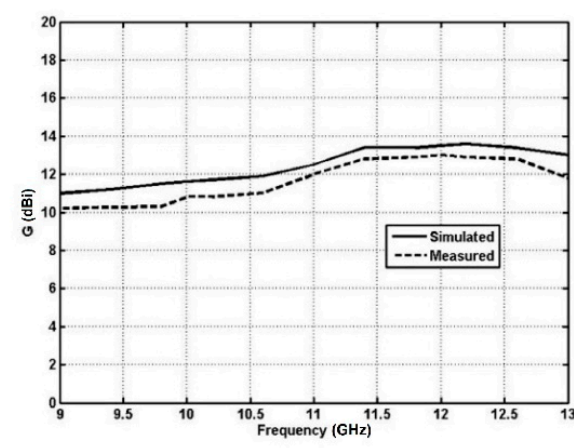

(b)

Figure 10. Simulated (solid curve) and measured (dashed curve) $\left|S_{11}\right|$ scattering parameters (a) and gain $G(b)$ versus the frequency of the $2 \times 2$ antenna array.

For the prototype of the $2 \times 2$ antenna array, Figure 11a,b show the simulated (solid curves) and measured (dashed curves) gain $\mathrm{G}$, at the frequency $\mathrm{f}=11.7 \mathrm{GHz}$, in azimuth $\mathrm{y}$-z plane and in elevation $\mathrm{x}-\mathrm{z}$ plane, respectively. The half power beam width $\mathrm{HPBW}=37.8^{\circ}$ was measured at the frequency 
$\mathrm{f}=11.7 \mathrm{GHz}$ in the azimuth $\mathrm{y}-\mathrm{z}$ plane. The radiation pattern and gain measurements were performed with StarLab Antenna Measurement Systems-Satimo@.

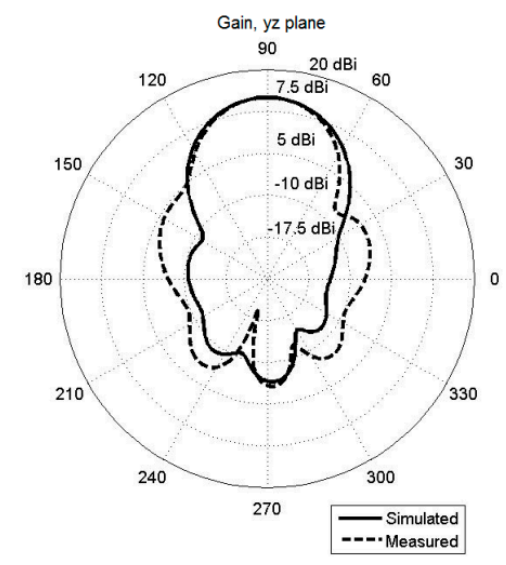

(a)

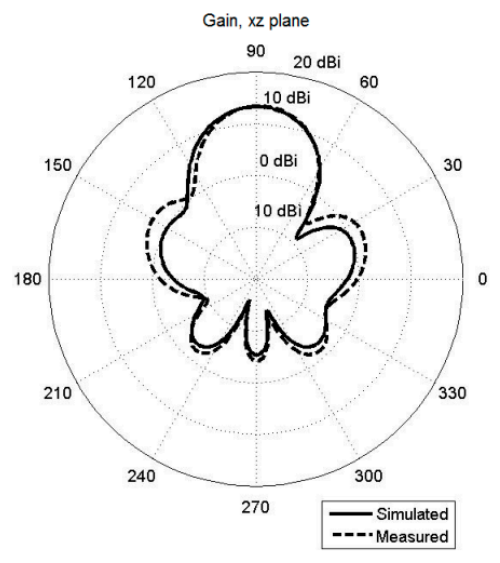

(b)

Figure 11. Radiation pattern of the $2 \times 2$ antenna array at $f=11.7 \mathrm{GHz}$ in the $y-z$ plane $(\mathbf{a})$ and the $x-z$ plane $(\mathbf{b})$.

The $4 \times 4$ array was constructed, see the prototype in Figure 12, by repeating the $2 \times 2$ base cell in both the $x$ and $y$ directions; then characterized, see Figure 13, which illustrates the anechoic chamber.

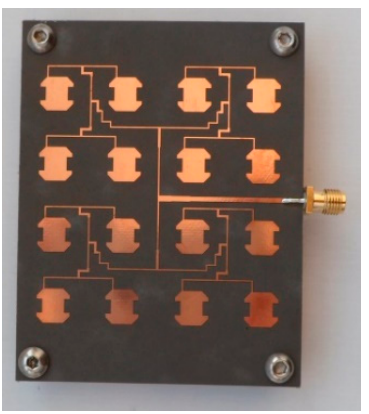

(a)

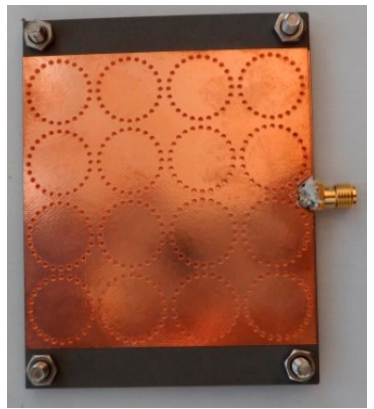

(b)

Figure 12. Prototype of the $4 \times 4$, dual layer, SIW cavity backed antenna array: (a) top view; (b) bottom view.

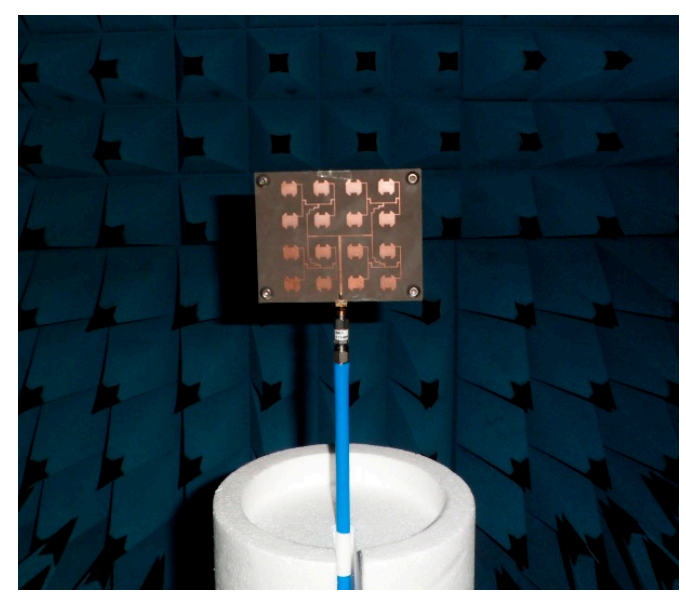

Figure 13. Radiated gain measurement of the $4 \times 4$ array antenna made with StarLab Antenna Measurement Systems-Satimo@ 
The measured (dashed curves) and simulated (solid curves) gain $G$ pattern in the azimuth $y-z$ plane and in the elevation $x-z$ plane are reported in Figure 14a,b, respectively. In both cases, the figures show good agreement between the simulation and measurement. As expected, by increasing the number of the array elements, a narrower shape (pencil like) of the radiating main lobe occurred. In fact, for the $4 \times 4$ array, a half power beam width (HPBW) of $19.6^{\circ}$ at the frequency $\mathrm{f}=11.7 \mathrm{GHz}$ was measured.

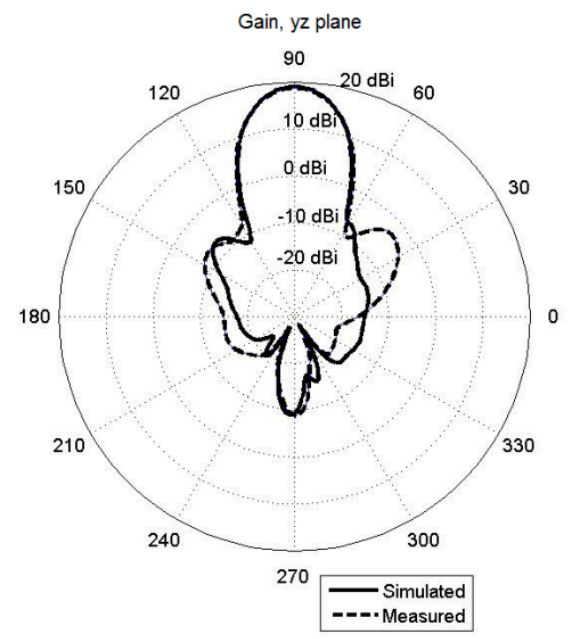

(a)

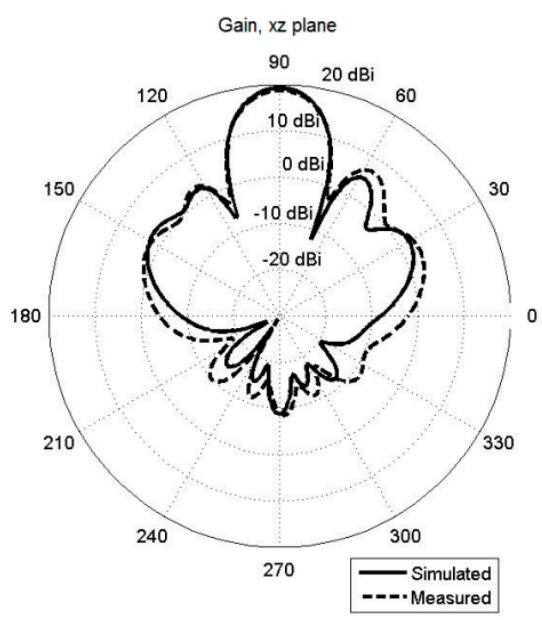

(b)

Figure 14. Radiation pattern of the $4 \times 4$ antenna array gain at $\mathrm{f}=11.7 \mathrm{GHz}$ in the $\mathrm{y}-\mathrm{z}$ plane (a) and $\mathrm{x}-\mathrm{z}$ plane (b).

The simulated (solid curve) and measured (dashed curve) gain for the $4 \times 4$ array versus the frequency is illustrated in Figure 15. The highest measured gain was $\mathrm{G}=18.7 \mathrm{dBi}$ at a $12.5 \mathrm{GHz}$.

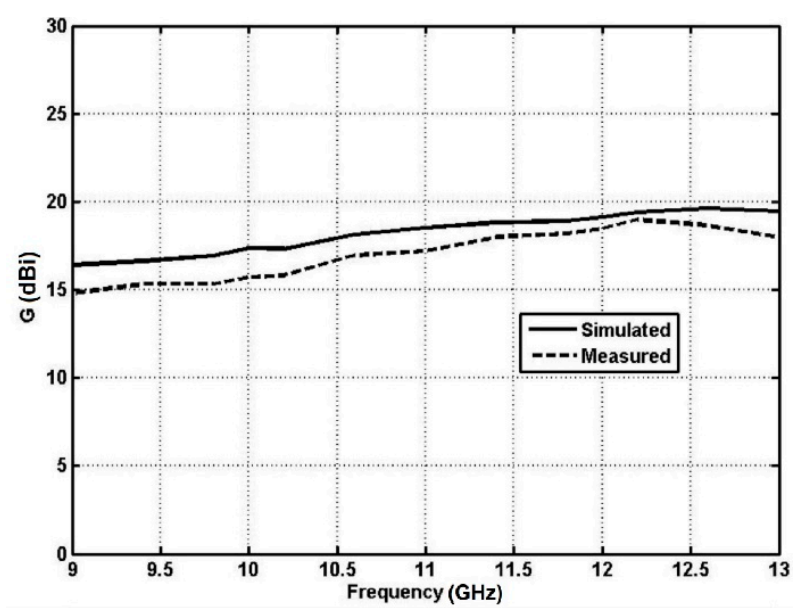

Figure 15. Simulated and measured gain $\mathrm{G}$ of the $4 \times 4$ antenna versus the frequency.

The $8 \times 8$ antenna array was constructed as seen in the prototype shown in Figure 16. Figure 17a shows the simulated (solid curve) and measured (dashed curve) modulus of the $S_{11}$ scattering parameter versus the frequency for the $8 \times 8$ antenna array. $\mathrm{A}-10 \mathrm{~dB}$ bandwidth was about 3 . A little ripple of the measured modulus of the $S_{11}$ scattering parameter occurred close to the frequency $\mathrm{f}=10.55 \mathrm{GHz}$ and is most likely due to the thin air gap between the two layers fixed with external screws. A similar ripple can be obtained via simulation by considering an air gap $\mathrm{g}=0.068 \mathrm{~mm}$. This problem can be avoided by integrating the two layers via a prepreg/press procedure. In Figure 17b, a difference of about $1.7 \mathrm{dBi}$ between the simulated and measured gain occurred. The difference 
between the simulated and measured gain was due to the manufacturing tolerance. For the $8 \times 8$ antenna array, the measured maximum gain was $\mathrm{G}=23.8 \mathrm{dBi}$ at a $12.5 \mathrm{GHz}$. The gain $\mathrm{G}$ is practically coincident with the results reported in [26] while the bandwidth 9.5-12.7 GHz almost doubled with respect to the antenna reported in [26]. The radiation gain of the array $8 \times 8$ in the $y-z$ and $x-z$ planes is shown in Figure 18a,b, respectively. The half power beam width in the azimuth $y-z$ plane measured at a frequency of $11.7 \mathrm{GHz}$ was HPBW $=9.5^{\circ}$. The maximum gain of the main lobe at the frequency $\mathrm{f}=11.7 \mathrm{GHz}$ was $\mathrm{G}=22.6 \mathrm{dBi}$, the first side lobe level was $-12.9 \mathrm{dBi}$.

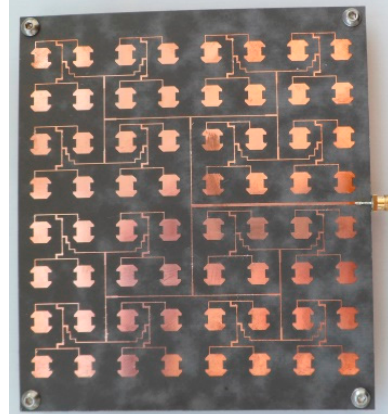

(a)

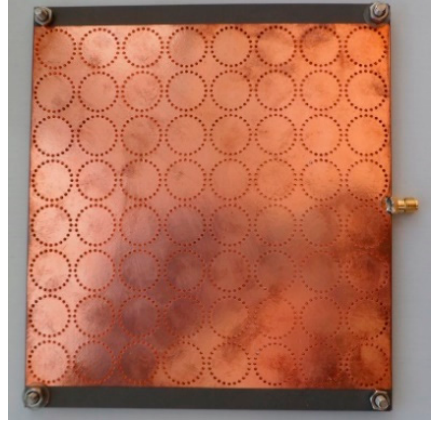

(b)

Figure 16. Prototype of the $8 \times 8$, dual layer, SIW cavity backed antenna array: (a) top view; (b) bottom view.

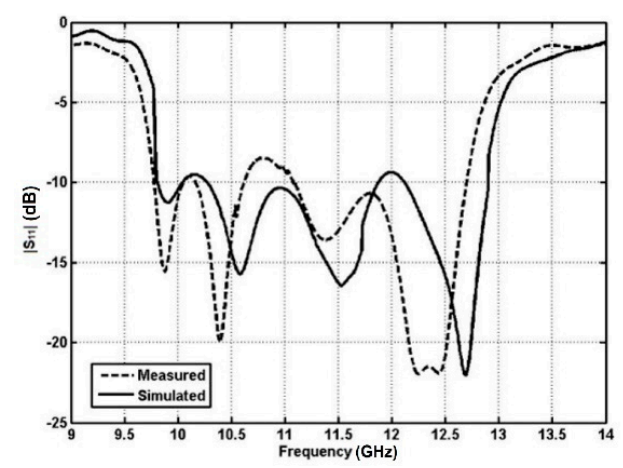

(a)

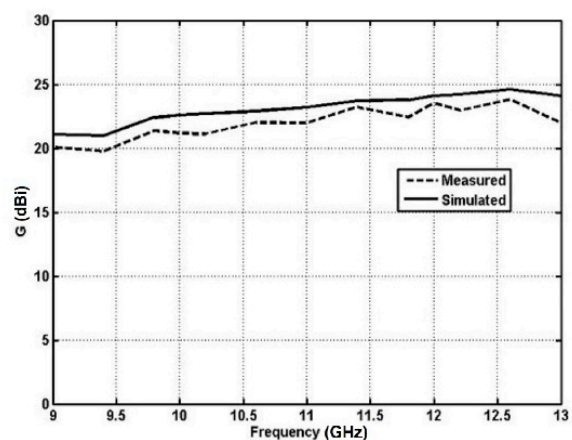

(b)

Figure 17. Simulated (solid curve) and measured (dashed curve) $\left|S_{11}\right|$ scattering parameters (a) and gain $G(b)$ versus the frequency for the $8 \times 8$ antenna array.

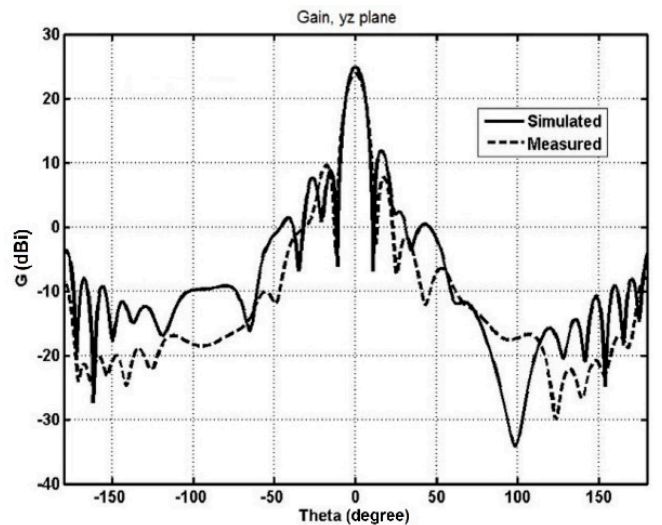

(a)

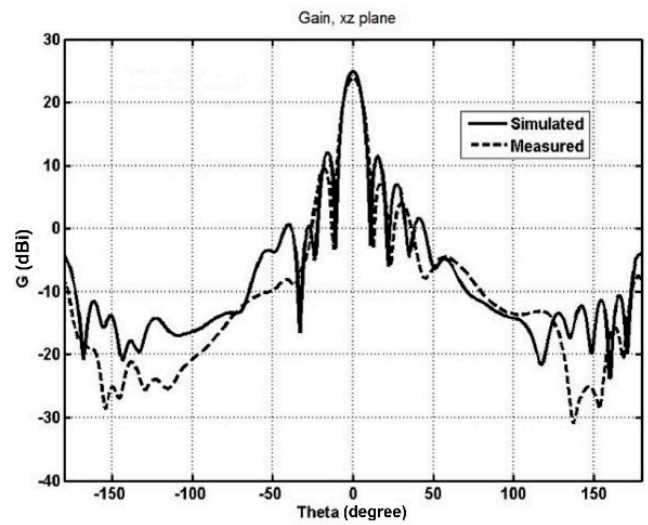

(b)

Figure 18. Radiation pattern of the $8 \times 8$ antenna array gain at $\mathrm{f}=11.7 \mathrm{GHz}$ in the $\mathrm{y}-\mathrm{z}$ plane (a) and the $\mathrm{x}-\mathrm{z}$ plane $(\mathbf{b})$. 
In actual satellite application, a gain of about $\mathrm{G}=30 \mathrm{dBi}$ and a band of at least $2 \mathrm{GHz}$ is required. A wider bandwidth is welcome to increase the communication capacity. To definitively prove the practical interest toward this kind of antenna $[18,26,28,29]$ the investigation was further extended and an array with 256 elements $(16 \times 16$ array) was built (see the prototype of Figure 19). Figure 20a shows good agreement between the simulated and measured $S_{11}$ in a very wide range of frequencies (at $-10 \mathrm{~dB}$, the range was about $9.8-12.6 \mathrm{GHz}$ ). A flat behavior of the measured and simulated gain, with a difference of about $2.4 \mathrm{dBi}$ between the two curves, is apparent in Figure 20b. The maximum gain value measured was obtained at a frequency of $12.6 \mathrm{GHz}$ and it was close to $\mathrm{G}=29.2 \mathrm{dBi}$. The simulated 3D radiated gain at a frequency of $\mathrm{f}=11.8 \mathrm{GHz}$ obtained with CST Microwave Studio $\odot$ is shown in Figure 21, the maximum simulated gain was $\mathrm{G}=30.59 \mathrm{dBi}$. The radiated gain measurement was made with a StarLab Antenna Measurement Systems-Satimo $\odot$ anechoic chamber as shown in Figure 22. Figure 23a,b show the agreement between the simulated and measured gain $G$ in azimuth $y-z$ plane, and in elevation $x-z$, respectively, at a frequency of $f=11.8 \mathrm{GHz}$. A half power beam width (HPBW) of $4.8^{\circ}$ was measured at a frequency of $11.8 \mathrm{GHz}$ in the azimuth $\mathrm{y}-\mathrm{z}$ plane. The measured gain at a frequency of $\mathrm{f}=11.8 \mathrm{GHz}$ was $26.8 \mathrm{dBi}$. Figure 24 shows the cross polarization of the $16 \times 16$ array. The measured cross-polarization at a frequency of $\mathrm{f}=11.8 \mathrm{GHz}$ was $-10 \mathrm{~dB}$.

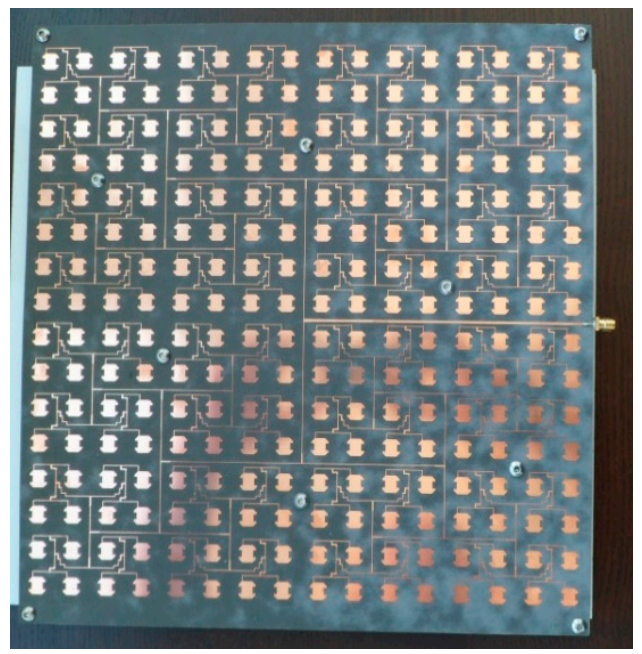

(a)

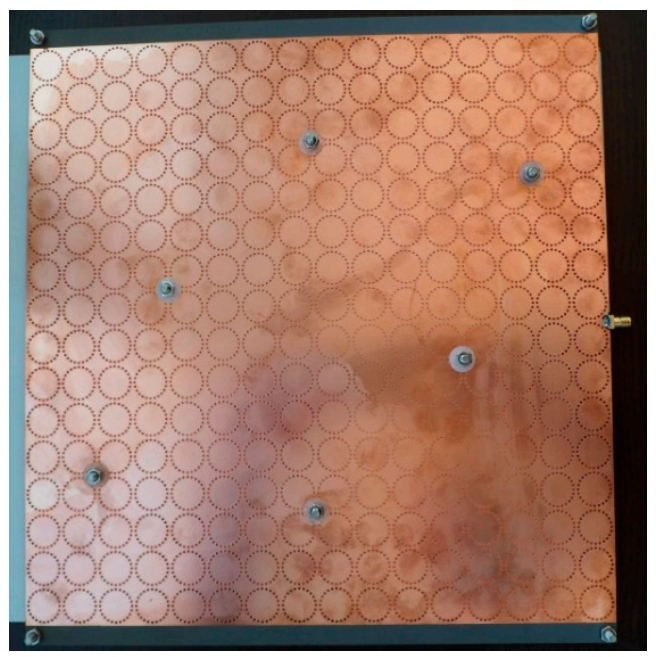

(b)

Figure 19. Prototype of the $16 \times 16$, dual layer, SIW cavity backed antenna array: (a) top view; (b) bottom view.

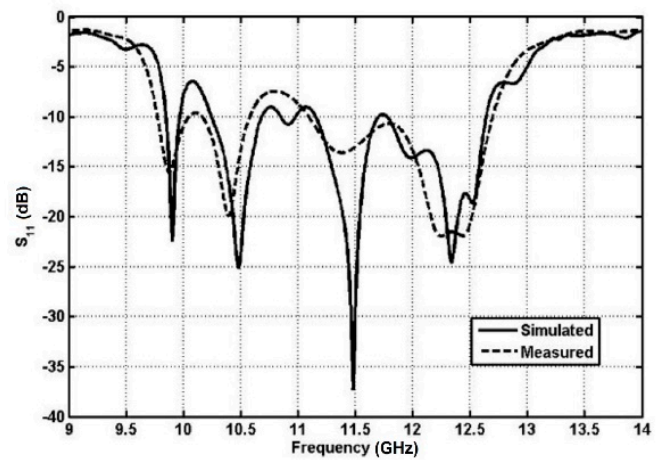

(a)

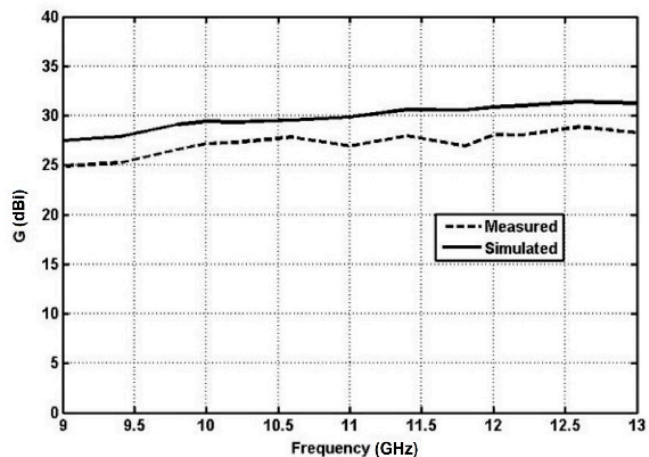

(b)

Figure 20. Simulated (solid curve) and measured (dashed curve) $\left|S_{11}\right|$ scattering parameters (a) and gain $G(b)$ versus the frequency for the $16 \times 16$ antenna array. 


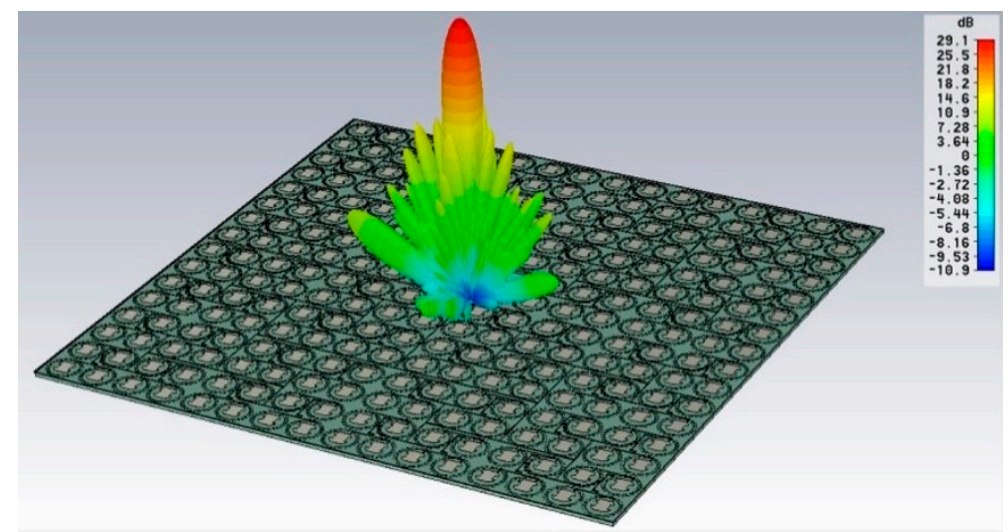

Figure 21. Simulation of the $3 \mathrm{D}$ radiated gain at a frequency of $f=11.8 \mathrm{GHz}$ obtained with CST Microwave Studio $\subset$. The maximum gain was $\mathrm{G}=30.59 \mathrm{dBi}$.

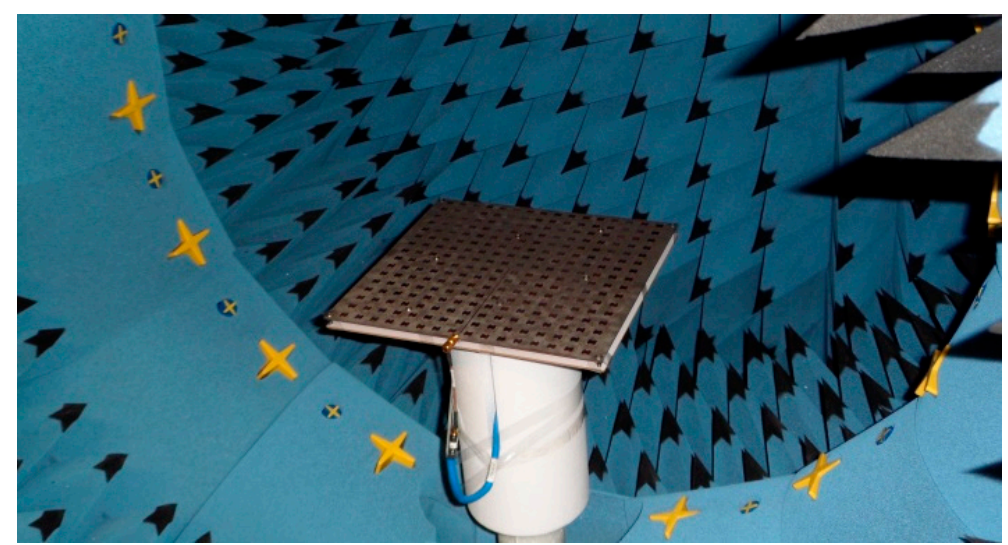

Figure 22. Radiated gain measurement of the $16 \times 16$ array antenna made with StarLab Antenna Measurement Systems-Satimo@.

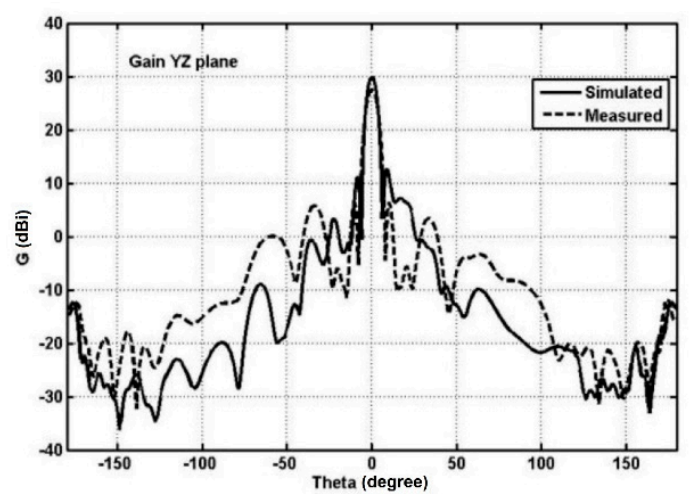

(a)

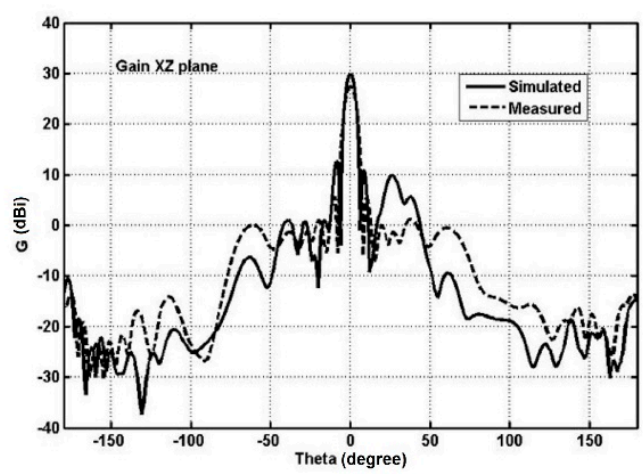

(b)

Figure 23. Radiation pattern of the $16 \times 16$ antenna array gain at $f=11.8 \mathrm{GHz}$ in the $y-z$ plane (a) and the $\mathrm{x}-\mathrm{z}$ plane $(\mathbf{b})$.

By increasing the number of the array elements, the insertion losses due to the larger feeding network and the coupling among the feeding lines and the radiating elements cannot be neglected. In fact, by increasing the number of array elements, the antenna radiation efficiency decreases. In particular, the measured efficiencies for the $2 \times 2,4 \times 4,8 \times 8$, and $16 \times 16$ arrays were $93 \%, 89 \%$, $69 \%$, and $52 \%$, respectively, at a frequency of $11.7 \mathrm{GHz}$ where the maximum gain was obtained. Even if these values are larger with respect to those reported in [26], the efficiency behavior was confirmed. 
By considering the beam shape, the negligible main lobe squint and the other measured characteristics, these planar antenna arrays seem very promising and are feasible for applications in the field of satellite communication.

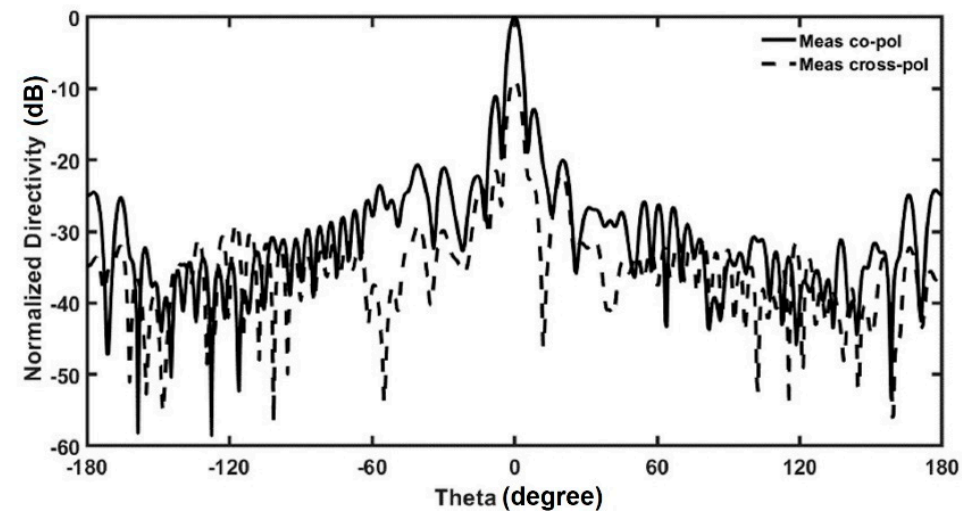

Figure 24. Cross polarization measurement of the $16 \times 16$ antenna array gain at $\mathrm{f}=11.8 \mathrm{GHz}$.

\section{Feasibility and Discussion on Material Choice}

The SIW cavity-backed $16 \times 16$ antenna array optimized for the Ku band operated well, providing a good gain and a wide band. The cost reduction was another important factor. The PCB technology can be employed for large scale and low cost production. A sample without screws to assembly the layers was engineered via the prepreg press compression molding procedure starting from four different layers. This confirmed the same characteristics of gain and bandwidth and is illustrated in Figure 25.

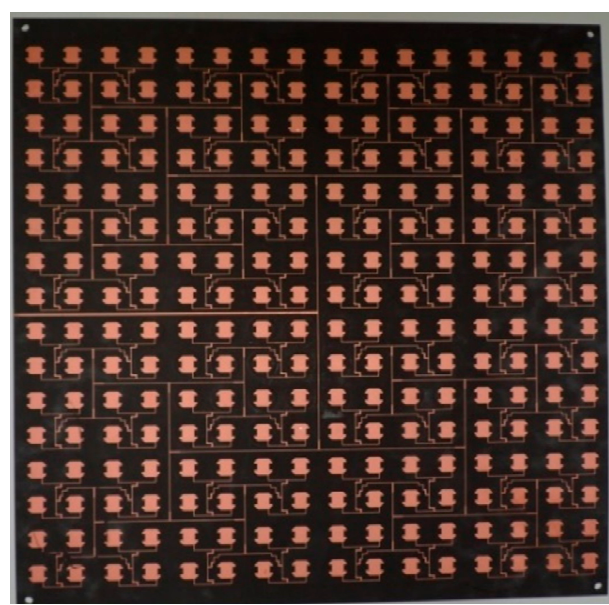

(a)

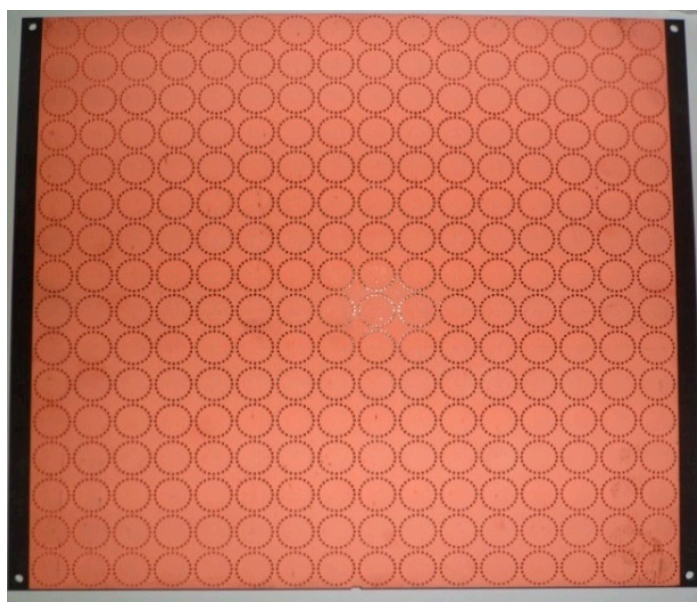

(b)

Figure 25. Engineered prototype, Rogers Duroid 5880, $16 \times 16$, dual layer, SIW cavity backed antenna array: (a) top view; (b) bottom view.

However, this kind of antenna is actually interesting for niche applications, when a low profile/small thickness/flat shape is strictly required and not for typical domestic applications. In fact, the cost of the employed Rogers Duroid 5880 layers makes the antenna array not competitive with respect to the conventional parabolic antenna. A lot of work has been devoted to understand whether a similar antenna could substitute the conventional parabolic one by considering different materials. We designed, fabricated, and characterized another antenna by employing Taconic RF35 A2 as the substrate material, which has a lower cost. The geometry was accurately optimized by considering the intermediate steps of $2 \times 2,4 \times 4,8 \times 8$, and $16 \times 16$. First, the prototype with the layers assembled with screws and then the engineered one were constructed, as shown in Figures 26 and 27. 
They exhibited similar performances that were unfortunately quite low, with a gain less than $23 \mathrm{dBi}$. Therefore, these prototypes are less interesting for actual applications.

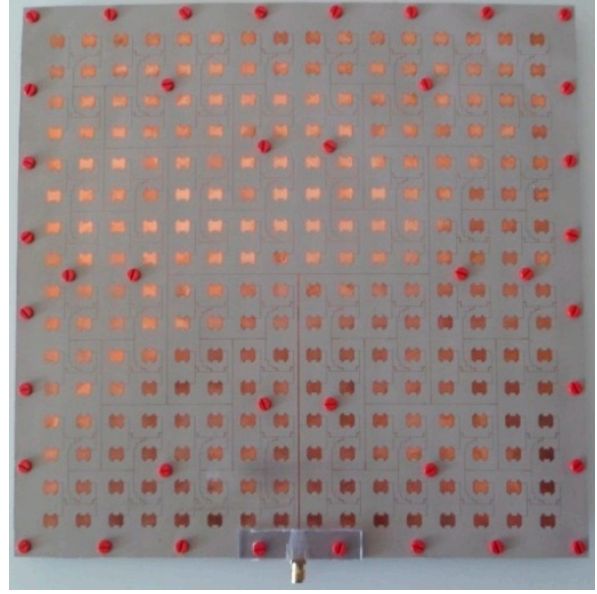

(a)

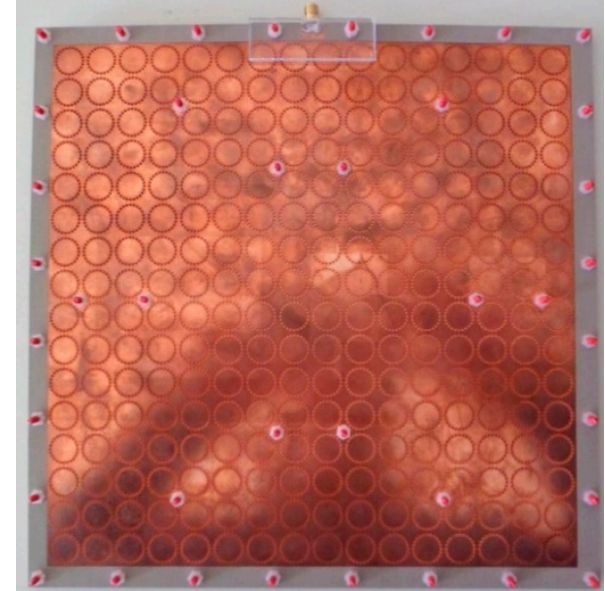

(b)

Figure 26. Assembled prototype with screws, Taconic RF35 A2, $16 \times 16$, dual layer, SIW cavity backed antenna array: (a) top view; (b) bottom view.

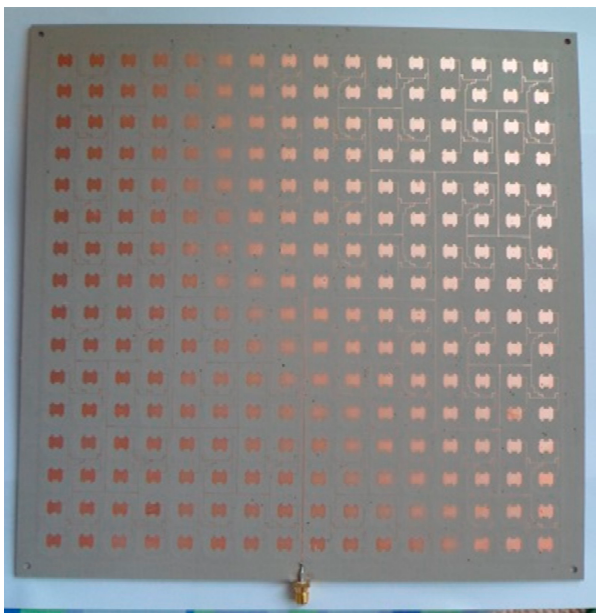

(a)

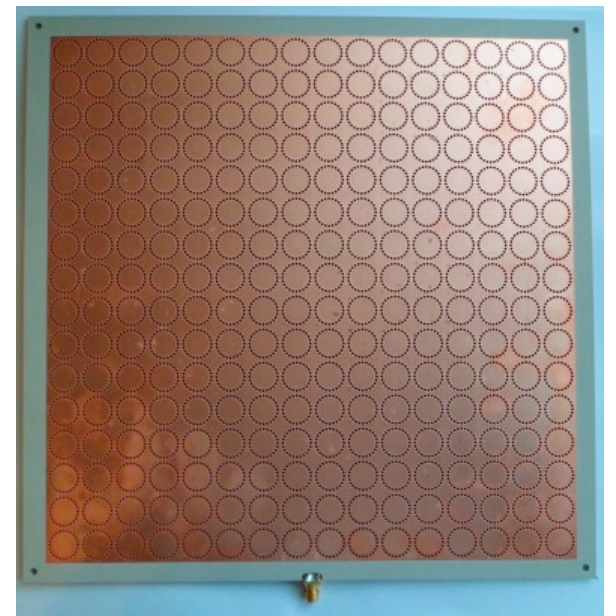

(b)

Figure 27. Engineered prototype, Taconic RF35 A2, $16 \times 16$, dual layer, SIW cavity backed antenna array: (a) top view; (b) bottom view.

\section{Conclusions}

A SIW cavity-backed patch antenna array was designed and optimized for operation in the Ku band. The design aimed to achieve a broad bandwidth, high gain, and low-cost implementation. A square patch antenna with all corners truncated and with two cuts on the sides was designed and a SIW backing cavity was optimized to increase the radiation performance. Standard, low cost PCB technology was employed for fabricating the prototypes.

The characterization of the antenna bandwidth and gain, performed with a StarLab Antenna Measurement Systems-Satimo@ had good agreement with the simulation performed with CST Studio 2013․ The array with 256 elements $(16 \times 16$ array) operated in a very wide range of frequencies of about $4 \mathrm{GHz}$ with a flat gain. The half power beam width (HPBW) was about $4.8^{\circ}$. By considering the beam shape, the negligible main lobe squint, and the other measured characteristics, these planar antenna arrays seem feasible for niche applications in the field of satellite communication when a low profile/small thickness/flat shape is required. 
Author Contributions: Conceptualization, Investigation, and Methodology, O.L., G.V., D.M., V.P., and F.P.; Writing-Original Draft Preparation, O.L., F.P.; Review and Editing, all authors; Supervision, F.P.

Funding: This research received no external funding.

Acknowledgments: This work has been partially supported within the MIUR plan: PON01_01224 Sviluppo di tecnologie in guida d'onda integrata (SIW) per applicazioni ICT a microonde.

Conflicts of Interest: The authors declare no conflict of interest.

\section{References}

1. Zavosh, F.; Aberle, J.T. Improving the performance of microstrip-patch antennas. IEEE Antennas Propag. Mag. 1996, 38, 7-12. [CrossRef]

2. Schellenberg, J.M. CAD models for suspended and inverted microstrip. IEEE Trans. Microw. Theory Tech. 1995, 43, 1247-1252. [CrossRef]

3. Chen, Z.N.; Chia, M.Y.W. Broadband suspended plate antenna with probe-fed strip. IEEE Proc.-Microw. Antennas Propag. 2001, 148, 37-40. [CrossRef]

4. Maillouk, R.J. On the use of metallized cavities in printed slot arrays with dielectric substrates. IEEE Trans. Antennas Propag. 1987, 35, 477-487. [CrossRef]

5. Luo, G.Q.; Hu, Z.F.; Dong, L.X.; Sun, L.L. Planar slot antenna backed by substrate integrated waveguide cavity. IEEE Antennas Wirel. Propag. Lett. 2008, 7, 236-239.

6. Li, R.L.; Pan, B.; Traille, A.N.; Papapolymerou, J.; Laskar, J.; Tentzeris, M.M. Development of a cavity-backed broadband circularly polarized slot/strip loop antenna with a simple feeding structure. IEEE Trans. Antennas Propag. 2008, 56, 312-318. [CrossRef]

7. Zavosh, F.; Aberle, J.T. Single and stacked circular microstrip patch antennas backed by a circular cavity. IEEE Trans. Antennas Propag. 1995, 43, 746-750. [CrossRef]

8. Bozzi, M.; Georgiadis, A.; Wu, K. Review of substrate-integrated waveguide circuits and antennas. IET Microw. Antennas Propag. 2011, 5, 909-920. [CrossRef]

9. Deslandes, D.; Wu, K. Single-substrate integration technique of planar circuits and waveguide filters. IEEE Trans. Microw. Theory Tech. 2003, 51, 593-596. [CrossRef]

10. Zhou, Y.; Huang, Y.M.; Jin, H.; Ding, S.; Xu, D.; Silvestri, L.; Bozzi, M.; Perregrini, L. Slow-Wave Half-Mode Substrate Integrated Waveguide 3dB Wilkinson Power Divider/Combiner Incorporating Non-Periodic Patterning. IEEE Microw. Wirel. Compon. Lett. 2018, 28, 765-767. [CrossRef]

11. Castellano, T.; Losito, O.; Mescia, L.; Chiapperino, M.A.; Venanzoni, G.; Mencarelli, D.; Angeloni, G.; Renghini, C.; Carta, P.; Prudenzano, F. Feasibility Investigation of Low Cost Substrate Integrated Waveguide (SIW) Directional Couplers. Prog. Electromagn. Res. B 2014, 59, 31-44. [CrossRef]

12. Glise, A.; Quéré, Y.; Maalouf, A.; Rius, E.; Castel, V.; Laur, V.; Sauvage, R.M. LDS Realization of High-Q SIW Millimeter Wave Filters with Cyclo-Olefin Polymers. Appl. Sci. 2018, 8, 2230. [CrossRef]

13. Steeg, M.; Yonemoto, N.; Tebart, J.; Stöhr, A. Substrate-Integrated Waveguide PCB Leaky-Wave Antenna Design Providing Multiple Steerable Beams in the V-Band. Electronics 2017, 6, 107. [CrossRef]

14. Hesari, S.S.; Bornemann, J. Antipodal Vivaldi Antenna Arrays Fed by Substrate Integrated Waveguide Right-Angled Power Dividers. Appl. Sci. 2018, 8, 2625. [CrossRef]

15. Cao, H.; Jiang, F.; Liu, J.; Cai, W.; Tang, M.; Tan, X.; Yang, S. A CSRR-Fed SIW Cavity-Backed Fractal Patch Antenna for Wireless Energy Harvesting and Communication. Sensors 2015, 15, 21196-21203. [CrossRef]

16. Saghati, A.P.; Entesari, K.A. Reconfigurable SIW Cavity-Backed Slot Antenna with One Octave Tuning Range. IEEE Trans. Antennas Propag. 2013, 61, 3937-3945. [CrossRef]

17. Liu, W.; Chen, Z.N.; See, T.S.P.; Liu, F. SIW-Slot-Fed Thin Beam-Squint-Free Fabry-Pérot Cavity Antenna with Low Backlobe Levels. IEEE Antennas Wirel. Propag. Lett. 2014, 13, 552-554. [CrossRef]

18. Awida, M.H.; Fathy, A.E. Substrate-Integrated Waveguide Ku-Band Cavity-Backed $2 \times 2$ Microstrip Patch Array Antenna. IEEE Antennas Wirel. Propag. Lett. 2009, 8, 1054-1056. [CrossRef]

19. Kim, D.Y.; Lee, J.W.; Lee, T.K.; Cho, C.S. Design of SIW Cavity-Backed Circular-Polarized Antennas Using Two Different Feeding Transitions. IEEE Trans. Antennas Propag. 2011, 59, 1398-1403. [CrossRef]

20. Lee, B.; Kang, G.C.; Yang, S.H. Broadband high-efficiency microstrip antenna array with corporate-series-feed. Microw. Opt. Technol. Lett. 2004, 43, 181-183. [CrossRef] 
21. Abdel-Wahab, W.M.; Wang, Y.; Safavi-Naeini, S. SIW hybrid feeding network-integrated 2-D DRA array: Simulations and experiments. IEEE Antennas Wirel. Propag. Lett. 2016, 15, 548-551. [CrossRef]

22. Lee, H.; Sung, Y.; Wu, C.T.M.; Itoh, T. Dual-Band and Polarization-Flexible Cavity Antenna Based on Substrate Integrated Waveguide. IEEE Antennas Wirel. Propag. Lett. 2016, 15, 488-491. [CrossRef]

23. Zhu, Q.; Ng, K.B.; Chan, C.H.; Luk, K.M. Substrate-Integrated-Waveguide-Fed Array Antenna Covering 57-71 GHz Band for 5G Applications. IEEE Trans. Antennas Propag. 2017, 65, 6298-6306. [CrossRef]

24. Srivastava, G.; Mohan, A. High gain SIW cavity backed differential slot antenna for X-band application. Electron. Lett. 2018, 54, 1361-1362. [CrossRef]

25. Li, W.; Xu, K.D.; Tang, X.; Yang, Y.; Liu, Y.; Liu, Q.H. Substrate Integrated Waveguide Cavity-Backed Slot Array Antenna Using High Order Radiation Modes for Dual-Band Applications in K-Band. IEEE Trans. Antennas Propag. 2017, 65, 4556-4565. [CrossRef]

26. Awida, M.H.; Suleiman, S.H.; Fathy, A.E. Substrate-Integrated Cavity-Backed Patch Arrays: A Low-Cost Approach for Bandwidth Enhancement. IEEE Trans. Antennas Propag. 2011, 59, 1155-1163. [CrossRef]

27. Awida, M.H.; Fathy, A.E. Design guidelines of substrate-integrated cavity backed patch antennas. IET Microw. Antennas Propag. 2012, 6, 151-157. [CrossRef]

28. Losito, O.; Mescia, L.; Mencarelli, D.; Venanzoni, G.; Prudenzano, F. SIW Cavity-Backed Patch Antenna for $\mathrm{Ku}$ Band Applications. In Proceedings of the 7th European Conference on Antennas and Propagation (EuCAP), Gothenburg, Sweden, 8-12 April 2013.

29. Losito, O.; Mescia, L.; Chiapperino, M.A.; Castellano, T.; Venanzoni, G.; Mencarelli, D.; Angeloni, G.; Carta, P.; Starace, E.M.; Prudenzano, F. X-Band SIW Cavity-Backed Patch Antenna for Radar Applications. In Proceedings of the EuMW 2013, Nuremberg, Germany, 6-11 October 2013.

(C) 2019 by the authors. Licensee MDPI, Basel, Switzerland. This article is an open access article distributed under the terms and conditions of the Creative Commons Attribution (CC BY) license (http:/ / creativecommons.org/licenses/by/4.0/). 